\title{
Primary malignant melanoma of the vagina: A case report and review of literature
}

\author{
Snehamay Chaudhuri, Diptimay Das', Soham Chowdhury, Anjan Das Gupta
}

\begin{abstract}
A 60 year old woman presented in gynecology department with bleeding per vagina and subsequently histotpathologically, it was diagnosed as malignant melanoma of the vagina. She underwent excision biopsy. On metastatic work-up, Positron emission tomography (PET) scan proved that she had distant metastasis and received palliative radiotherapy and chemotherapy, with temozolamide. She is alive after one year.
\end{abstract}

Key words: Malignant melanoma, melanoma, vagina

\section{Introduction}

Malignant melanoma of vagina is a rare tumor with an incidence of only 0.46 cases per one million women per year ${ }^{[1]}$ and less than 250 cases are reported in literature to date. ${ }^{[2,3]}$ It accounts for less than $1 \%$ of all malignant melanoma and less than $3 \%$ of all primary malignant tumors of the vagina. ${ }^{[4]}$ This aggressive tumor has a poor prognosis with 5 year survival rate $5-25 \% .^{[4-6]}$ The optimal treatment of vaginal melanoma is a subject of debate. ${ }^{[7]}$ We present a case of primary vaginal malignant melanoma located in lower one third of vagina and review the current literature.

\section{Case Report}

A 60 year old woman, $\mathrm{P} 2+0$, post-menopausal by 20 years, presented in gynecology department with the complaints of white discharge and recurrent small amount of bleeding per vagina for last 3 months. The patient was hypertensive, diabetic and had total abdominal hysterectomy with bilateral salpingo oophorectomy 20 years ago. Per speculum vaginal examination revealed, a brown colored, firm nodule of $1 \mathrm{~cm}^{2}$ at lower $1 / 3^{\text {rd }}$ postero lateral vaginal wall without any surrounding vaginal colour changes. Bilateral parametria were free and rectum was normal and there was no inguinal lymphadenopathy. Wide local excision biopsy (Free margin $1 \mathrm{~cm}$ ) was done and sent for histopathological examinations. Unfortunately we lost follow up of the patient for next six weeks and she returned with histopatological report of lesion of malignant melanoma of vaginal mucosa. At this point, her vaginal

Departments of Obstetrics and Gynecology, 'Radiotherapy, NRS

Medical College, Kolkata, West Bengal, India

Correspondence to: Dr. Snehamay Chaudhuri,

E-mail: snehamay_chaudhuri_dr@yahoo.com

\begin{tabular}{|l|l|}
\hline \multicolumn{2}{|c|}{ Access this article online } \\
\hline Quick Response Code: & Website: \\
\hline & \\
\hline
\end{tabular}

examination revealed healing of the wound site with presence of indurations and diffuse black colour change of both lower $1 / 3^{\text {rd }}$ of anterior and posterior vaginal wall [Figure 1]. MRI pelvis revealed a $3 \times 1.9 \times 1.6 \mathrm{~cm}$ mass in the posterolateral vagina with bilateral reactive lymph nodes in inguinal region.

Metastatic work up was done. PET scan revealed an ill-defined soft tissue mass in mid vagina involving left lateral wall $(1.5 \times 1.2 \mathrm{~cm})$ standard uptake value $(\mathrm{SUV}=5.6)$ with perilesional fat plane preserved. Irregular linear uptake of 18 fluro deoxy glucose (FDG) (SUV 9.7) was found along left vaginal wall with no obvious CT scan lesion. Few subcentimeter lymph nodes (SUV 2.3) were also present in both inguinal and external iliac region.

Patchy linear uptake (SUV 6.0) was found in right rectus abdominis muscle, with bilateral subcarinal lymph nodes (SUV 6.2) and another lesion was found in the infraumbilical region. However, definitive evidence of metastasis was not histopathologically confirmed by FNAC or excision biopsy.

The patient was treated with external beam radiotherapy (40 Gy in 10 fractions; 2 fractions per week) with palliative intent to the tumor bed, followed chemotherapy with six cycles of Temozolamide, $250 \mathrm{mg}$

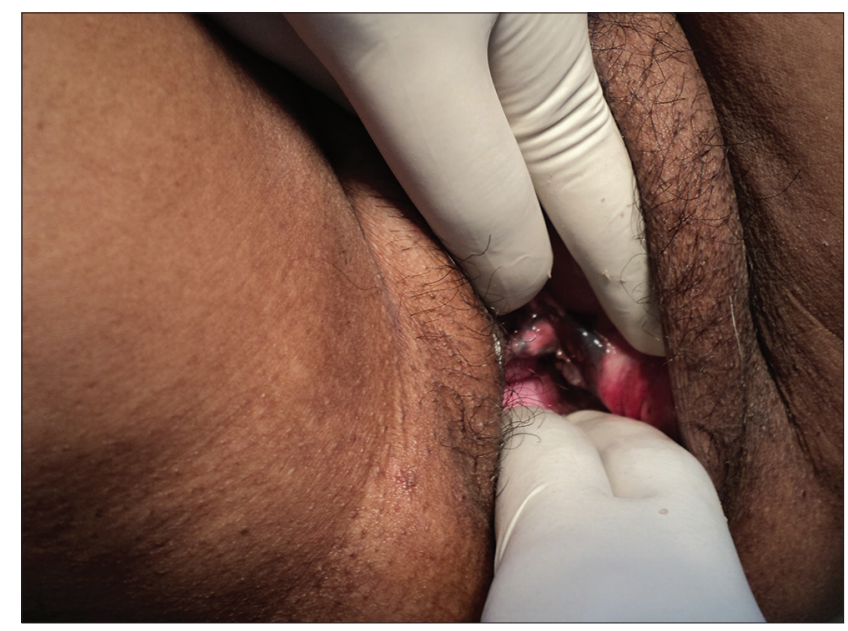

Figure 1: Diffuse black pigmentation of vaginal mucosa 
orally for 5 days, per cycle. The patient is alive after 1 year and under follow up [Figure 2].

\section{Discussion}

Primary malignant melanoma is a rare entity first reported by Poronas in $1887 .{ }^{[8]}$ The tumor typically presents in the sixth and seventh decades of life and occurs more commonly in the lower $1 / 3^{\text {rd }}$ of the vagina and mostly in the anterior vaginal wall. ${ }^{[4]}$ It affects post- menopausal women and does not have any known risk factors. ${ }^{[9]}$ The most common symptoms are vaginal bleeding, vaginal discharge and feeling a mass in the vagina. ${ }^{[4]}$ Grossly, the tumour is polypoid to nodular in the majority of cases. ${ }^{[10]}$ The appearance of the tumor is almost always pigmented and only $10-23 \%$ are amelanotic. ${ }^{[11]}$ The peculiarity in presentation of our case is that on initial examination it presented as a brown colored nodular growth in the posterolateral vaginal wall and subsequently after excision biopsy it spread quickly as a diffuse lesion which was dark black in colour. The literature is scarce on this issue. The natural course of malignant melanomas is marked by early local recurrence, extensions and frequent metastases to the lymph nodes, viscera and also life threatening hemorrhage, making it the most dangerous form of vaginal tumor. ${ }^{[12]}$ The differential diagnoses include metastasis from other sites, poorly differentiated squamous cell carcinoma, sarcoma, lymphoma and blue nevus. It has a high rate of recurrence and poor long term survival. ${ }^{[13]}$

The treatment modalities that are available include pelvic exenteration, radical surgery (total vaginectomy with or without vulvectomy), wide excision and non-surgical treatment (primary radiation therapy, chemotherapy or both). Wide excision may be wide radical excision or wide local excision where less than $2 \mathrm{~cm}$ circumferential margin is obtained because of difficult anatomic location of tumor. ${ }^{[5]}$ Although earlier reports have advocated radical surgery as the mainstay of therapy, the recurrence rate and survival are similar in patients who have undergone of radical surgery and local excision. ${ }^{[14]}$ The most recent

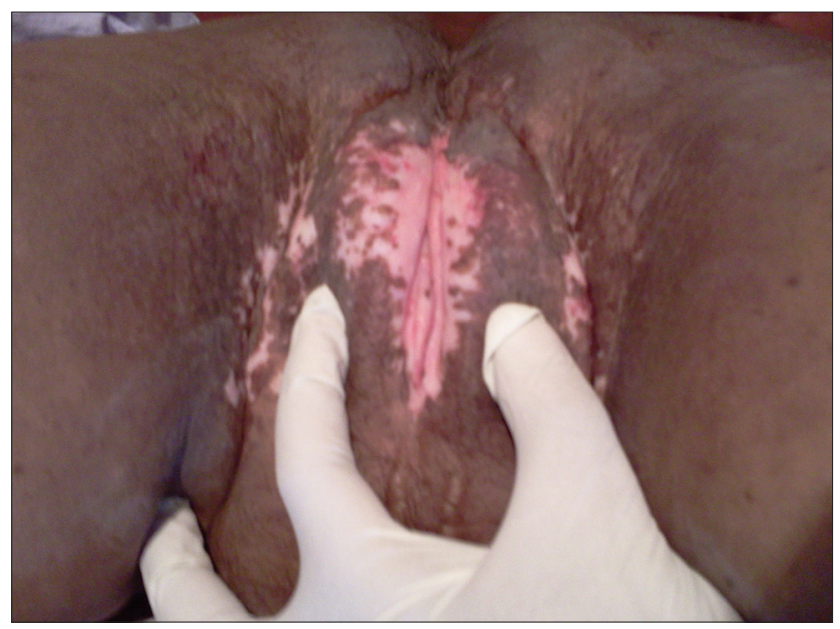

Figure 2: Follow up of the patient at one year data are in favour of a conservative approach and radiation therapy. ${ }^{[5,15]}$ Optimal treatment (radical surgery or radiotherapy) for an individual patient is a matter of controversy. ${ }^{[7]}$ Since distant metastases are a component in $78 \%$ cases of recurrence, adjuvant systemic therapy might be warranted in these high risk cases. Multiple traditional cytotoxic agents, including decarbazine, temozolomide, and platinum compounds, nitrosoureas and taxanes, both as single agents and in combination, have been evaluated in the treatment of melanoma, with limited or no success. The response rate of these single agent is $11-22 \%$ with median overall survival of 5.6-11 months. ${ }^{[7]}$ In our patient, Temozolamide was selected in view of less toxicity, better efficacy and ease of oral administration at home. The addition of interleukin- 2 to traditional cytotoxic agents has failed to show an improvement in overall survival but has considerably increased toxicity. ${ }^{[16]}$ The prognosis of vaginal melanoma is very poor, regardless the treatment modality, because most cases are diagnosed at a late stage. ${ }^{[17]}$

In conclusion, the most accepted treatment of malignant melanoma of the vagina is surgery and post-operative radiotherapy. Primary malignant melanoma of the vagina has a poor prognosis with high risk of local recurrence and distant metastasis. In our case, local excision followed by radiotherapy and chemotherapy was a tolerable treatment.

\section{References}

1. Hu DN, Yu GP, McCormick SA. Population based incidence of vulvar and vaginal melanoma in various races and ethnic groups and comparison of other site specific maelanoma. Melanoma Res 2010;20:153-8.

2. Fulciniti F, Ascierto PA, Simeone E, Bove P, Lodito S, Russo S, et al. Nevoid melanoma of vagina: Report of one case diagnosed on thin layer cytological preparations. Cytojournal 2007;4:14.

3. Piura B, Rabinovich, Yanai-Inber I. A Primary malignant melanoma of vagina: Case report and review of literature. Eur J Gynaecol Oncol 2002;23: 195-8.

4. Samolis S, Panagopoulos P, Kanellopoullos N, Papastefanou I, Karadaglis S, Katsoulis M. Primary malignant melanoma of vagina: Case report. Eur J Gynaecol Oncol 2010;31;233-4.

5. Michael F, Mariano E, Charlotte CS, Pamela TS, Patricea JE, Charles FL, et al. Primary malignant melanoma of vagina. Obstet Gynecol 2010;116:1358-65.

6. Tjalma WA, Monagham JM, de Barros Lopes A, Naik R, Nordin A. Primary vaginal melanoma and long term survivors. Eur J Gynaecol Oncol 2001;22:20-2.

7. Lin LT, Liu CB, Chen SN, Chiang AJ, Liou WS, Yu KJ. Primry malignant melanoma of the vagina with repeated local recurrences and brain metastasis. J Chin Med Assoc 2011;74:376-9.

8. Manlucu ED, Dickson H, Mahmood L, Nath ME. Case 167 - Bloody vaginal discharge, final diagnosis, primary malignant melanoma of vagina (Online). Available from: http://path.upmc.edu/cases / case 167/dx.html. [Last accessed on 2012 Jan 28].

9. Baloglu A, Bezircioglu I, Cetinkaya B, Yavuzcan A. Promary malignant melanoma of the vagina. Arch Gynecol Obstet 2009;280:819-22.

10. Gupta D, Malpica A, Deavers MT, Silva EG. Vaginal melanoma: A clinicopathologic and immunohistochemical study of 26 cases. Am J Surg Pathol 2002;26:1450-7.

11. Miner TJ, Delgado R, Zeisler J, Busam K, Alektiar K, Barakat R, et al. Primary vaginal melanoma: A critical analysis of therapy. Ann Surg Oncol 2004;11:34-9.

12. McKinnan JG, Kokal WA, Neifeld JP. Natural history and treatment of mucosal melanoma. J Surg Oncol 1989;41:222-5.

13. Moros ML, Ferrer FP, Mitchell MJ, Romeo JA, Lacruz RL. Primary 
malignant melanoma of vagina - poor response to radical surgery and adjuvant therapy. Eur J Obstet Gynecol Reprod Biol 2004;113:248-50.

14. Fallahian $\mathrm{M}$, Zare $\mathrm{KH}$. Multifocal malignant melanoma of female genital tract. Iran J Med Sci 2006;31:235-7.

15. Petru E, Nagele F, Czerwenka K. Primary malignant melanoma of vagina: Long term remission following radiation therapy. Gynecol Oncol 1998;70:23-6.

16. Rosenberg SA, Yang JC, Schwartzentruber DJ, Hwu P, Marincola FM, Topalian SL, et al. Prospective randomized trial of the treatment of patients with metastatic melanoma using chemotherapy with cisplatin, decabazine and tamoxifen alone or in combination with interleukin 2 and interferon alfa - 2b. J Clin Oncol 1999;17:968-75.

17. Androutsopoulos G, Adonakis G, Ravazoula P, Kourounis G. Primary malignant melanoma of vagina: A case report. Eur J Gynaecol Oncol 2005;26:661-2.

How to site this article: Chaudhuri S, Das D, Chowdhury S, Gupta AD. Primary malignant melanoma of the vagina: A case report and review of literature. South Asian J Cancer 2013;2:4.

Source of Support: Nil. Conflict of Interest: None declared.

\section{Announcement}

"ICONs Dr Arun Kurkure Prize for Best Paper in IJC on Women's Cancer"

In memory of late Dr Arun Kurkure, ICON has announced the constitution of this prize for the best paper on Womens cancer published in the Indian Journal of Cancer in a calendar year.

It will include a certificate and cash educational grant of Rs 50,000/-.

The winner will be selected by a special committee - from all the papers published on women's cancer in each calendar year.

The winner will be invited to make a presentation at a conference/meeting of ICON or co-sponsored by ICON. After his/her presentation, the winner will also be given the certificate and prize cheque at the same meeting.

for further details, please contact: Dr Khurshid Mistry at khurshid.mistry@oncologyindia.org 